Research Paper

\title{
Combined administration of taurine and monoisoamyl DMSA protects arsenic induced oxidative injury in rats
}

\author{
Swaran J.S. Flora, * Swapnila Chouhan, Gurusamy M. Kannan, Megha Mittal and Harimohan Swarnkar
}

Department of Pharmacology and Toxicology; Defence Research and Development Establishment; Gwalior India

Abbreviations: $\delta$-ALAD, delta-aminolevulinic acid dehydratase; AAS, atomic absorption spectrophotometer; As, arsenic; DMSA, meso 2,3-dimercaptosuccinic acid; GSH, reduced glutathione; GSSG, oxidized glutathione; SOD, superoxide dismutase; Hb, haemoglobin; $\mathrm{MCH}$, mean cell haemoglobin; MCHC, mean cell haemoglobin concentration; MCV, mean cell volume; MiADMSA, monoisoamyl 2,3-dimercaptosuccinic acid; -PCV, packed cell volume; RBC, red blood cell; ROS, reactive oxygen species; TBARS, thiobarbituric acid reactive substances; WBC, white blood corpuscles; ZPP, zinc protoporphyrin

Key words: arsenic toxicity, oxidative stress, taurine, chelation

Arsenic is a naturally occurring element that is ubiquitously present in the environment. High concentration of naturally occurring arsenic in drinking water is a major health problem in different parts of the world. Despite arsenic being a health hazard and a well documented carcinogen, no safe, effective and specific preventive or therapeutic measures are available. Among various recent strategies adopted, administration of an antioxidant has been reported to be the most effective. The present study was designed to evaluate the therapeutic efficacy of monoisoamyl dimercaptosuccinic acid (MiADMSA), administered either individually or in combination with taurine post chronic arsenic exposure in rats. Arsenic exposed male rats $(25 \mathrm{ppm}$, sodium arsenite in drinking water for 24 weeks) were treated with taurine $(100 \mathrm{mg} / \mathrm{kg}$, i.p., once daily), monoisoamyl dimercaptosuccinic acid (MiADMSA) $(50 \mathrm{mg} / \mathrm{kg}$, oral, once daily) either individually or in combination for 5 consecutive days. Biochemical variables indicative of oxidative stress along-with arsenic concentration in blood, liver and kidney were measured. Arsenic exposure significantly reduced blood $\delta$-aminolevulinic acid dehydratase (ALAD) activity, a key enzyme involved in the heme biosynthesis and enhanced zinc protoporphyrin (ZPP) level. Clinical hematological variables like white blood cells (WBC), mean cell hemoglobin (MCH), and mean cell hemoglobin concentration (MCHC) showed significant decrease with a significant elevation in platelet (PLT) count. These changes were accompanied by significant decrease in superoxide dismutase (SOD) activity and increased catalase activity. Arsenic exposure caused a significant decrease in hepatic and renal glutathione (GSH) level and an increase in oxidized glutathione (GSSG). These

\footnotetext{
${ }^{*}$ Correspondence to: Swaran J.S. Flora; Department of Pharmacology and Toxicology; Defence Research and Development Establishment; Jhansi Road; Gwalior 474002 India; Tel.: +91.751.2344301; Fax: +91.751.2341148; Email: sjsflora@hotmail. com, sjsflora@drde.drdo.in

Submitted: 05/15/08; Revised: 06/03/08; Accepted: 06/16/08

Previously published online as an Oxidative Medicine and Cellular Longevity E-publication: www.landesbioscience.com/journals/oximed/article/6481
}

biochemical changes were correlated with an increased uptake of arsenic in blood, liver and kidney. Administration of taurine significantly reduced hepatic oxidative stress however co-administration of a higher dose of taurine $(100 \mathrm{mg} / \mathrm{kg})$ and MiADMSA provided more pronounced effects in improving the antioxidant status of liver and kidney and reducing body arsenic burden compared to the individual treatment of MiADMSA or taurine. The results suggest that in order to achieve better effects of chelation therapy, co-administration of taurine with MiADMSA might be preferred.

\section{Introduction}

The drinking water containing arsenic more than $10 \mu \mathrm{g} / \mathrm{L}$ is harmful to the body. ${ }^{1}$ The main source of this arsenic contamination is the shallow tube wells, having more than $500 \mu \mathrm{g} / \mathrm{L}$ of arsenic. ${ }^{2}$ Heavy reliance of agriculture on new water wells has lead to extensive chronic arsenic poisoning in certain parts of countries like Bangladesh, India (West Bengal) and China (Inner Mongolia). ${ }^{3,4}$ In addition to the natural sources of arsenic contamination in drinking water, use of arsenic-containing herbicides, insecticides, rodenticides, preservatives and by-products of fossil fuels are enough to challenge the aquatic environment as well as humankind. ${ }^{5}$ Arsenic induced oxidative stress in blood and other soft tissues has been postulated to be one of the possible mechanisms of arsenic induced toxic effects. ${ }^{6-9}$ Disruption of pro-oxidant/antioxidant balance might lead to tissue injury. An increased arsenic concentration has been shown to be accompanied by increased lipid per-oxidation in animal tissues. ${ }^{10}$ Exposure to sodium arsenite has been reported to significantly decrease glutathione (GSH) level, superoxide dismutase (SOD), glutathione peroxidase (GPx) and catalase activity. ${ }^{9}$ Maiti and Chatterjee ${ }^{11}$ reported that liver and kidneys have different adaptive cellular protective mechanism against arsenic exposure.

The current approved clinical intervention against arsenic toxicity is to give chelating agents which form an insoluble complex with arsenic and remove it from the burdened tissues. Most of these chelating agents however, suffer from serious side effects. ${ }^{12,13}$ Clinical reliance on meso 2,3-dimercaptosuccinic acid (DMSA), an orally administered chelator, has expanded greatly during the last few years 
particularly after it was approved for the clinical use against childhood lead poisoning by US Food and Drug Administration (FDA). ${ }^{14}$ DMSA is one of the least toxic drugs that could be given orally; a less obvious benefit may also be derived as a result of DMSA's structural potential to serve as an antioxidant in vivo ${ }^{15}$ however, use of DMSA is compromised with some limitations. Hydrophilic and lipophobic properties of DMSA do not allow it to pass through cell membrane. It was recently reported that the monoesters of DMSA might be more effective chelating agent for metal poisoning than DMSA. ${ }^{16,17}$ Mono isoamyl ester of DMSA (MiADMSA) is a C5 branched chain ester (Fig. 1) that has been found to be more effective than DMSA in reducing lead, mercury and cadmium burden. ${ }^{13,18}$ Structure of MiADMSA comprises of straight and branched chain amyl group which helps in increasing its lipophilicity. Lipophilicity and molecular size of this new drug might be an important factors for the removal of arsenic from both intra-cellular sites possibly leading to better therapeutic efficacy. ${ }^{19}$ It has been observed that MiADMSA is more efficient in mobilizing brain lead than DMSA. ${ }^{20}$ It is believed that DMSA being relatively efficient and non-toxic chelator, MiADMSA should also be of greater interest particularly as a potential drug for chelation therapy in arsenic poisoning. One of the major drawbacks of chelation therapy is related to redistribution of toxic metals to other tissues, especially to the brain. ${ }^{5}$ No such redistribution was however, observed with MiADMSA administration. ${ }^{21}$ Mehta and Flora ${ }^{22}$ reported that administration of MiADMSA may lead to copper loss and also mild hepatotoxicity. It indicates greater complexing potential of DMSA monoester compared to DMSA. The depletion of essential metals does not necessarily result in the pronounced excretion of the metal in the urine. A number of previous reports have indicated an increased uptake of zinc and copper with no alteration in urinary copper and zinc following DMSA administration. ${ }^{23}$ It has also been reported that chelator is relatively safe during late gestation and it does not cause any major alteration in the mothers and the developing pups. ${ }^{24}$ Despite a few drawbacks/side effects associated with MiADMSA, MiADMSA is being considered recently as a future drug of choice owing to its specificity, accessibility to intracellular spaces and the absence of essential metal redistribution. ${ }^{22-24}$ Moderate toxicity followed by administration of MiADMSA may be reversible after withdrawal of chelating agent.

As mentioned above, arsenic induced oxidative stress is one of the possible mechanisms involved in the pathogenesis of arsenic poisoning. Thus, it is believed that supplementation of an antioxidant during treatment should be one of the important components of an effective arsenic therapy. Some of the antioxidants like $\mathrm{n}$-acetylcysteine (NAC) have been proved to be beneficial both in reducing oxidative stress and arsenic burden. ${ }^{15}$ Such dual benefits of these chelators and/or antioxidant support their use in combination. This may support the theory (combination treatment) for a more effective treatment of arsenic poisoning compared to their individual treatment.

Taurine is a naturally occurring antioxidant and a drug used for the treatment of diabetic polyneuropathy (structure shown in Fig. 1). ${ }^{25}$ It has a thiol group and found naturally in plants and animals. Taurine is a sulphur containing $\delta$-amino acid found in millimolar concentrations especially in tissues that are excitable, rich in membranes and generates oxidants. ${ }^{26}$ The sulfonate group in taurine is a strong acid that makes it completely zwitterionic

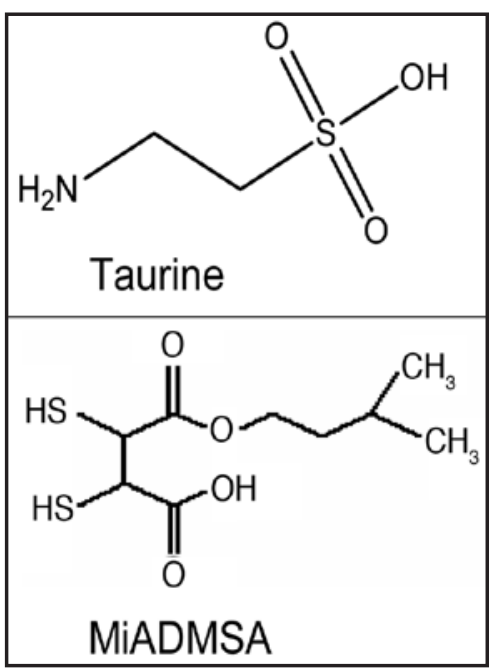

Figure 1. Chemical structure of taurine and MiADMSA.

over the physiological $\mathrm{pH}$ range. ${ }^{27}$ Taurine is known to maintain calcium homeostasis, osmoregulation, removal of hypochlorous acid, and stabilizing the membranes. ${ }^{27}$ It's potential as a chelating agent against lead poisoning has been reported by us. ${ }^{28}$ We concluded that the administration of taurine exerts no influence on blood and soft tissue lead levels, but recommended its use as a therapeutic intervention in lead poisoning, particularly in combination with a chelator. Taurine was also shown to form less stable metal complexes with various transition metals such as $\mathrm{Cu}^{+2}, \mathrm{Ni}^{+2}, \mathrm{Zn}^{+2}, \mathrm{Fe}^{+2}, \mathrm{Mg}^{+2}$, $\mathrm{Mn}^{+2}$, compared to other amino acids. Direct interaction between taurine and metal ions is mainly attributed to the electric association between metal cations and the sulfonate anion or to the interaction between metal ions and the nitrogen's unshared pair of electrons. ${ }^{26}$

The present study was thus planned to investigate the therapeutic efficacy of taurine in combination with MiADMSA on altered biochemical variables suggestive of oxidative stress and arsenic concentration in blood and tissues post chronic arsenic exposed rats.

\section{Results}

Data indicative of alterations in heme biosynthesis pathway and oxidative stress in arsenic exposed rats and after treatment with taurine, MiADMSA either individually or in combination, is shown in Table 1. Exposure to arsenic significantly decreased blood ALAD activity and increased ZPP level while, GSH concentration showed marginal depletion. Administration of taurine $(100 \mathrm{mg} /$ $\mathrm{kg}$ ) and MiADMSA individually, had no effect on inhibited blood ALAD activity, ZPP and GSH levels except for a moderate beneficial effect of MiADMSA when administered alone on blood ZPP levels. Combined administration of lower dose of taurine $(50 \mathrm{mg} / \mathrm{kg})$ with MiADMSA was effective in increasing blood ALAD and depleting ZPP level although the effects were statistically non significant. On the other hand, combined administration of a higher dose of taurine $(100 \mathrm{mg} / \mathrm{kg})$ with MiADMSA led to a more pronounced beneficial effects on ALAD activity and GSH levels compared to all other treatments. Neither MiADMSA nor the combination treatments with taurine were effective in reducing ZPP level towards the normal value. 
Table 1 Effects of MiADMSA and taurine co-administration on some arsenic sensitive biochemical variables suggestive of altered heme biosynthesis pathway and oxidative stress

\begin{tabular}{lccc}
\hline & $\begin{array}{c}\text { ALAD } \\
\text { (nmol/min/ml erythrocytes) }\end{array}$ & $\begin{array}{c}\text { ZPP } \\
(\mu \mathrm{mol} \mathrm{ZPP} / \mathbf{m o l} \text { heme) }\end{array}$ & $\begin{array}{c}\text { GSH } \\
(\mathbf{m g} / \mathbf{m l})\end{array}$ \\
Normal animals & $9.86 \pm 0.80^{*}$ & $61.0 \pm 0.66^{*}$ & $5.00 \pm 0.33^{*}$ \\
Arsenic, $25 \mathrm{ppm}$ & $4.30 \pm 0.17^{\dagger}$ & $96.3 \pm 6.11^{\dagger}$ & $4.38 \pm 0.62^{*}$ \\
Taurine, $100 \mathrm{mg} / \mathrm{kg}$ & $4.63 \pm 0.17^{\dagger}$ & $93.6 \pm 1.45^{\dagger}$ & $4.49 \pm 0.17^{*}$ \\
MiADMSA, $50 \mathrm{mg} / \mathrm{kg}$ & $5.00 \pm 0.10^{\dagger}$ & $79.0 \pm 3.00^{\dagger}$ & $4.89 \pm 0.08^{*}$ \\
MiADMSA + Taurine, $50 \mathrm{mg} / \mathrm{kg}$ & $5.60 \pm 0.13^{\dagger}$ & $83.3 \pm 10.4^{\dagger}$ & $4.84 \pm 0.07^{*}$ \\
MiADMSA + Taurine, $100 \mathrm{mg} / \mathrm{kg}$ & $8.10 \pm 0.70^{\ddagger}$ & $85.2 \pm 8.03^{\dagger}$ & $5.04 \pm 0.03^{*}$
\end{tabular}

ALAD, $\delta$-aminolevulinic acid dehydratase; ZPP, zinc protoporphyrin; GSH, reduced glutathione; MiADMSA, monoisoamyl dimercaptosuccinic acid; Values are mean $\pm S E ; n=5 ;{ }^{*}, t$, ${ }^{\ddagger}$ Means with matching symbol notations in each column are not significant at $5 \%$ level of significance.

Table 2 shows the effect of taurine and MiADMSA either individually or in combination on some selected clinical variables in blood. No significant change in the levels of RBC, Hb and HCT were noted however, WBC level decreased and PLT counts showed significant increase on arsenic exposure. None of the treatments were effective in influencing altered WBC and PLT levels.

Table 3 shows the effect of taurine and MiADMSA either individually or in combination on blood MCV, MCHC and MCH levels in arsenic pre-exposed rats. All the three parameters were significantly decreased on arsenic exposure. Taurine and MiADMSA individually had no effect on these altered clinical variables. Combined administration of a lower dose of taurine $(50 \mathrm{mg} / \mathrm{kg})$ with MiADMSA also had no beneficial effects on these variables while the administration of higher dose of taurine $(100 \mathrm{mg} / \mathrm{kg})$ with MiADMSA provided significant recovery in $\mathrm{MCHC}$ and $\mathrm{MCH}$ levels compared to all other treatments.

The levels of hepatic GSH, GSSG, and activities of SOD and catalase in animals exposed to arsenic and following treatment with taurine, and MiADMSA, either individually or in combination, are shown in Table 4. Exposure to arsenic significantly reduced hepatic GSH level and increased GSSG concentration while, liver SOD activity exhibited a decrease and catalase an increase. Administration of taurine was most effective compared to MiADMSA administration in significantly restoring catalase and SOD activities towards normal value. Treatment with MiADMSA alone provided most effective reversal in GSH and GSSG levels compared to individual treatment with taurine. Co-administration of taurine (particularly at the higher dose) and MiADMSA, on the other hand, provided more pronounced recovery in these variables compared to all other treatments (Table 4).

Data in Figure 2 depicts levels of GSH and GSSG in kidneys of arsenic exposed rats and following treatment with taurine and MiADMSA, either individually or in combination. Kidney GSH level decreased marginally while, GSSG level increased significantly on arsenic exposure. All the treatments were able to restore altered GSH level however GSSG level responded favorably only to the combined administration of MiADMSA and

taurine $(100 \mathrm{mg} / \mathrm{kg})$

Figure 3 shows arsenic concentration in blood, liver and kidney of arsenic exposed animals and the ability of taurine, and MiADMSA either alone or in combination to reduce its concentration. Administration of taurine alone had no effect on arsenic levels while administration of MiADMSA alone significantly reduced arsenic concentration of blood, liver, and kidney. Co-administration of taurine at higher dose $(100 \mathrm{mg} / \mathrm{kg})$ with MiADMSA provided the best effects in reducing arsenic concentration from these organs than any other treatments.

\section{Material and Methods}

Animals and treatments. Male wistar albino rats weighing approximately 110-120 g were obtained from the Defence Research and Development Establishment (DRDE) animal facility and prior to use, were acclimatized for 7 days $12 \mathrm{~h}$ light/dark cycle. The Animal Ethical Committee of the DRDE, Gwalior, India, approved the protocols for the experiments. Rats were divided into two groups of five and twenty five rats each and were treated as below for 24 consecutive weeks,

Group I: Normal animals (Received normal water)

Group II: As (25 ppm, as sodium meta-arsenite, in drinking water)

After 24 weeks of arsenic exposure, animals in Group II were subdivided into 5 groups of five animals each and treated as below, for 5 consecutive days:

Table 2 Effects of MiADMSA and taurine co-administration on some clinical hematological variables

\begin{tabular}{|c|c|c|c|c|c|}
\hline & $\begin{array}{c}\text { WBC } \\
\left(10^{3} / \mu \mathrm{l}\right)\end{array}$ & $\begin{array}{c}\text { RBC } \\
\left(10^{6} / \mu \mathrm{l}\right)\end{array}$ & $\begin{array}{c}\text { PLT } \\
\left(10^{6} / \mu\right)\end{array}$ & $\begin{array}{c}\mathrm{Hb} \\
(\mathrm{g} / \mathrm{dl})\end{array}$ & $\begin{array}{l}\text { HCT } \\
(\%)\end{array}$ \\
\hline Normal animals & $7.54 \pm 1.76^{*}$ & $5.0 \pm 0.88^{*}$ & $782 \pm 98 *$ & $11.6 \pm 0.21$ * & $37 \pm 5.3^{*}$ \\
\hline Arsenic, $25 \mathrm{ppm}$ & $3.65 \pm 0.31^{\dagger}$ & $6.4 \pm 0.25^{*}$ & $1203 \pm 126^{\dagger}$ & $11.9 \pm 0.60 *$ & $43 \pm 1.6^{*}$ \\
\hline Taurine, 100 mg/kg & $3.25 \pm 0.11^{\dagger}$ & $7.2 \pm 0.29 *$ & $918 \pm 64^{\dagger}$ & $13.2 \pm 0.36$ * & $47 \pm 1.1^{*}$ \\
\hline MiADMSA, $50 \mathrm{mg} / \mathrm{kg}$ & $2.95 \pm 0.61^{\dagger}$ & $6.7 \pm 0.28 *$ & $1227 \pm 75^{\dagger}$ & $12.3 \pm 0.01$ * & $45 \pm 0.7^{*}$ \\
\hline MiADMSA + Taurine 50 mg/kg & $3.75 \pm 0.83^{\dagger}$ & $6.7 \pm 0.26^{*}$ & $1012 \pm 191^{\dagger}$ & $12.4 \pm 0.56^{*}$ & $45 \pm 1.7^{*}$ \\
\hline MiADMSA + Taurine $100 \mathrm{mg} / \mathrm{kg}$ & $2.82 \pm 0.64^{\dagger}$ & $5.7 \pm 1.05^{*}$ & $1623 \pm 344^{\dagger}$ & $12.2 \pm 0.34^{*}$ & $38 \pm 5.8^{*}$ \\
\hline
\end{tabular}

WBC, white blood cells; RBC, red blood cells; PLT, platelet; Hb, Hemoglobin; HCT, hematocrit; MiADMSA, monoisoamyl dimercaptosuccinic acid; Values are mean $\pm S E ; n=5 ;{ }^{*},+$ Means with matching symbol notations in each column are not significant at $5 \%$ level of significance. 
Group IIA: saline

Group IIB: Taurine $(100 \mathrm{mg} / \mathrm{kg}$, i.p., once daily)

Group IIC: MiADMSA $(50 \mathrm{mg} / \mathrm{kg}$, orally once daily)

Group IID: MiADMSA (same as Gr. II C) + Taurine, $50 \mathrm{mg} / \mathrm{kg}$, i.p.

Group IIE: MiADMSA (same as Gr. II C) + Taurine, $100 \mathrm{mg} / \mathrm{kg}$, i.p.

Arsenic exposure was stopped during the course of chelation treatment. The doses for MiADMSA and taurine were selected based on previously reported studies. ${ }^{28,29}$ Doses of chelating agents and taurine were given 6 hours apart, on each day. Throughout the experiment the animals were kept on standard pellet diet (Amrut Feeds, Pranav Agro, New Delhi, metal contents of diet, in ppm dry weight $\mathrm{Zn} \mathrm{45,} \mathrm{Cu} \mathrm{10,} \mathrm{Mn} \mathrm{55,} \mathrm{Fe} \mathrm{70,} \mathrm{Co} \mathrm{5).}$ Animals were sacrificed under light ether anesthesia $48 \mathrm{~h}$ after the last dose. Blood was collected by cardiac puncture in heparinized tubes. Liver and kidney were removed, rinsed in cold saline, blotted, weighed and used for various biochemical variables and metal analysis. Half portion of the liver and one of the kidneys from each rat was processed immediately for biochemical estimation and the remaining was stored at $-20^{\circ} \mathrm{C}$ before wet acid digestion with $\mathrm{HNO}_{3}$ for estimation of arsenic contents.

Biochemical assays. The activity of blood ALAD was assayed according to the procedure of Berlin and Schaller. ${ }^{30}$ Zinc protoporphyrin (ZPP) was determined in a drop of blood with the help of a haematoflurometer (Model 2060, Aviv, Lakewood, USA) and a calibrated glass slide. ${ }^{31}$ For the determination of blood GSH concentration, the method of Ellman ${ }^{32}$ was followed, while for tissue (liver and kidneys) GSH and GSSG estimation, the procedure of Hissin and Hilf was followed. ${ }^{33}$ Superoxide dismutase (SOD) activity in liver was assayed spectrophotometrically as described by Durak et al. ${ }^{34}$ Catalase activity was assayed following the procedure of Aebi ${ }^{35}$ at room temperature. The molar extinction coefficient of $43.6 \mathrm{M}$ $\mathrm{cm}^{-1}$ was used to determine CAT activity. One unit of activity is equal to the moles of $\mathrm{H}_{2} \mathrm{O}_{2}$ degraded $/ \mathrm{min} / \mathrm{mg}$ protein. Tissue lipid oxidazibility was measured by shaking the liver homogenate in $150 \mathrm{mM} \mathrm{KCl}, 0.025 \mathrm{M}$ Tris- $\mathrm{HCl}$ buffer ( $\mathrm{pH} \mathrm{7.5)} \mathrm{for} 30 \mathrm{~min}$ at $37^{\circ} \mathrm{C}$ and measuring the lipid oxidation formed with the thiobarbituric acid reaction. ${ }^{36}$
For blood and tissues metal determination, wet tissue weight and volume of blood was recorded. After digestion with concentrated nitric acid using a microwave digestion system (model MDS-2100, CEM, USA), samples were brought to a constant volume and determination of tissue arsenic contents was performed using a hydride vapor generation system fitted with an atomic absorption spectrophotometer (AAS, Perkin Elmer model AAnalyst 100).

\section{Discussion}

The present study concludes beneficial role of taurine when administered along with MiADMSA in providing effective reversal of number of arsenic sensitive biochemical variables suggestive of oxidative stress and altered heme biosynthesis pathway. The data provides some interesting observations for suggesting an effective treatment for cases of chronic arsenic poisoning. We understand that extrapolating the animal data to human cases has its limitations particularly for the fact that similar signs and symptoms following chronic arsenic exposure in animal models are difficult. In human cases signs of chronic toxicity appear after long term exposure to a low dose of arsenic and thus we selected comparatively higher dose of arsenic in the present study in animal model for achieving the few similar effects which are seen in human cases. Shila et al. ${ }^{37}$ selected $100 \mathrm{ppm}$ dose of arsenite for a 8 weeks exposure in rats in order to evaluate alterations in glutathione level and its response to lipoic acid. For MiADMSA dose protocol, a dose of $50 \mathrm{mg} / \mathrm{kg}$ dose through oral route has been reported by us in the previous studies to be ideal to achieve the best therapeutic effects following arsenic

Table 4 Effects of MiADMSA and taurine co-administration on some biochemical variables suggestive of hepatic oxidative stress

\begin{tabular}{|c|c|c|c|c|}
\hline & $\begin{array}{c}\text { Catalase } \\
\text { ( } \mu \text { moles/min/mg protein) }\end{array}$ & $\begin{array}{c}\text { SOD } \\
\text { (units/min/mg protein) }\end{array}$ & $\begin{array}{c}\text { GSH } \\
(\mathrm{mg} / \mathrm{ml})\end{array}$ & $\begin{array}{c}\text { GSSG } \\
(\mathrm{mg} / \mathrm{ml})\end{array}$ \\
\hline Normal animals & $3.37 \pm 0.34^{*}$ & $0.49 \pm 0.03^{*}$ & $14.4 \pm 1.1^{*}$ & $0.84 \pm 0.06$ * \\
\hline Arsenic, 25 ppm & $7.36 \pm 0.62^{\dagger}$ & $0.18 \pm 0.03^{\dagger}$ & $8.5 \pm 1.2^{\dagger}$ & $1.97 \pm 0.47^{\dagger}$ \\
\hline Taurine, $100 \mathrm{mg} / \mathrm{kg}$ & $2.14 \pm 0.51 *$ & $0.34 \pm 0.03^{\ddagger}$ & $8.1 \pm 1.0^{\dagger}$ & $0.50 \pm 0.03^{\ddagger}$ \\
\hline MiADMSA, $50 \mathrm{mg} / \mathrm{kg}$ & $9.19 \pm 1.00^{\dagger}$ & $0.26 \pm 0.01^{\dagger}$ & $9.7 \pm 0.8^{\dagger}$ & $0.89 \pm 0.01$ * \\
\hline MiADMSA + Taurine $50 \mathrm{mg} / \mathrm{kg}$ & $2.98 \pm 0.29 *$ & $0.35 \pm 0.01 \ddagger$ & $9.5 \pm 0.9^{\dagger}$ & $0.72 \pm 0.14^{*}$ \\
\hline MiADMSA + Taurine, $100 \mathrm{mg} / \mathrm{kg}$ & $5.80 \pm 0.29 \ddagger$ & $0.22 \pm 0.01$ * & $11.7 \pm 0.6^{\ddagger}$ & $0.77 \pm 0.03^{*}$ \\
\hline
\end{tabular}

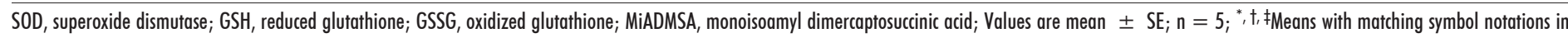
each column are not significant at $5 \%$ level of significance. 


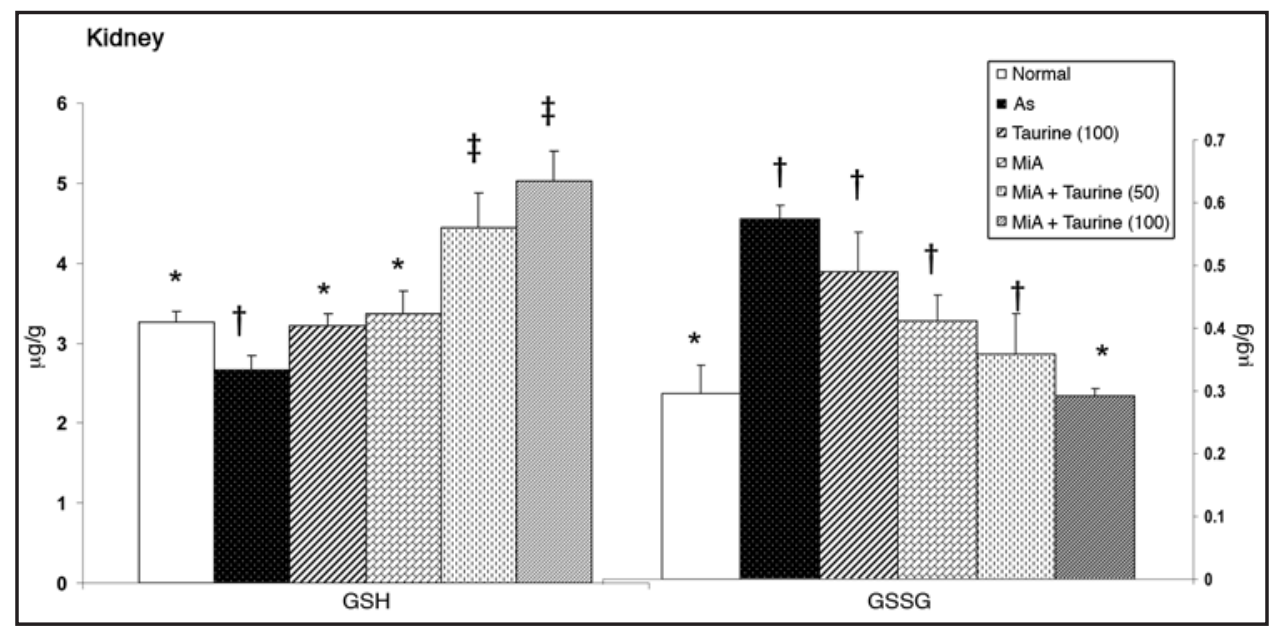

exposure including depletion of intracellular arsenic. ${ }^{38}$ Few recent studies reported the superior efficacy of monoisoamyl DMSA (MiADMSA) and mono-n-amyl DMSA in protecting the mice from the lethal effects of arsenic and in reducing body arsenic burden. ${ }^{38,39}$

Reactive oxygen species are thought to contribute to the pathogenesis of arsenic toxicity. ${ }^{40,41}$ Results from the present study also suggest that some of the toxic effects of arsenic could be attributed to the arsenic induced oxidative stress. A significant inhibition of blood ALAD and GSH level and an increase in ZPP level was noted in the present study. It is well known that arsenic affects the haematopoietic system by inhibiting the haem bio-synthesis. The enzyme that is sensitive to the toxic effects of arsenic is probably $\delta$-aminolevulinic acid dehydratase (ALAD). ALAD is a sulfhydryl-containing enzyme involved in the heme synthesis pathway, and its inhibition can be attributed to the binding of arsenic with sulfhydryl groups. Arsenic has got a high affinity for -SH group and it binds with reduced glutathione (GSH). Inhibition of ALAD enzyme by arsenic led to decreased heme synthesis and ultimately anemia. ALAD inactivation may also led to the accumulation of $\delta$-aminolevulinic acid that can cause an overproduction of ROS, which in part could explain arsenic induced oxidative stress. ${ }^{42}$ It has been reported earlier that this significant increase in ALA level might be a contributing factor in the induction of reactive oxygen species (ROS) generation. ${ }^{43-45}$ Considerable beneficial effects of taurine particularly at a dose

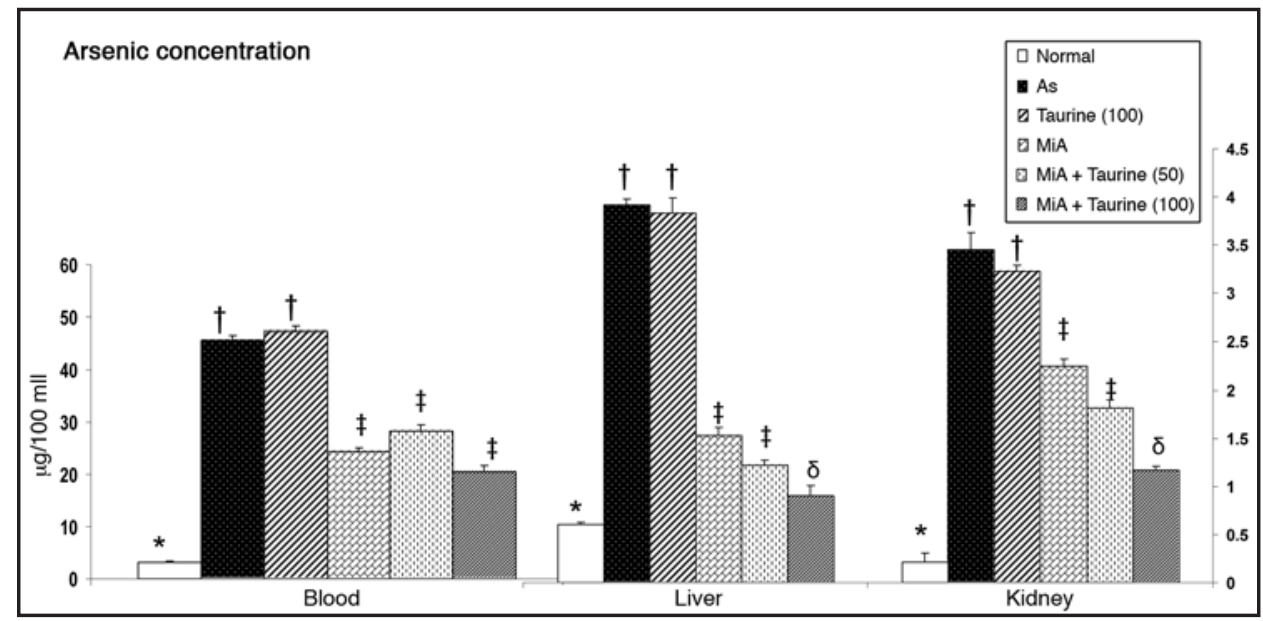

Figure 2. Effects of MiADMSA and taurine co-administration on some biochemical variables suggestive of renal oxidative stress in arsenic exposed rats. Figure shows oxidative stress condition by the depletion of GSH level and elevation of GSSG level and significant recovery by co-administration of higher dose of taurine $(100 \mathrm{mg} / \mathrm{kg}$ ) and MiADMSA. GSH, reduced glutathione; GSSG, oxidized glutathione. Values are mean $\pm \mathrm{SE} ; \mathrm{n}=5$. ${ }^{*}, t, \ddagger$ Means with matching symbol notations in each column are not significant at $5 \%$ level of significance

of $100 \mathrm{mg} / \mathrm{kg}$ were noted when it was administered along with MiADMSA on biochemical variables suggestive of oxidative stress. The reversal in the inhibited ALAD activity following treatment with MiADMSA might be attributed to the availability of thiol groups (Fig. 1). Co-administration of MiADMSA with taurine $(100 \mathrm{mg} /$ $\mathrm{kg}$ ) led to a more pronounced recovery in arsenic-induced oxidative injury compared to the individual effects of these drugs. These beneficial effects might be due to (i) depletion of body arsenic burden by MiADMSA and/or (ii) antioxidant action of taurine. ${ }^{28}$ Increased catalase activity and decreased SOD activity in liver was also noted following arsenic exposure. Role of taurine in maintaining GSH levels and increasing the status of antioxidant enzymes (SOD, Catalase and $\mathrm{GP}_{\mathrm{X}}$ ) by directly scavenging superoxide radicals and reducing cellular damage caused by free radicals have been reported earlier in lead exposed animals. ${ }^{46}$ It has been demonstrated that taurine acts as an antioxidant in vivo and in vitro studies. ${ }^{47}$ The mechanism of the possible antioxidative effects of taurine is unclear, but it has been suggested that the same is related to free radical scavenging activity of taurine. ${ }^{48}$ The free sulphydryl group in taurine seems to play a significant role as a ROS scavenger. Taurine is neither metabolized nor incorporated into cellular proteins in mammals suggesting ready availability of sulfhydryl moiety in cytosol. ${ }^{27,49}$ Antioxidant potential of taurine has also attributed to its ability to restore metal induced depletion of membrane $\mathrm{Na}^{+}$, $\mathrm{K}^{+}$-ATPase activity. ${ }^{50}$ Besides the above, mechanism for the antioxidant effect of taurine can also be explained as its direct action to quench and detoxify some reactive intermediate such as hypochlorous acid generated by myeloperoxidase, ${ }^{50}$ nitric oxide, ${ }^{51}$ and $\mathrm{H}_{2} \mathrm{O}_{2}{ }^{52}$ and indirectly via protecting cells through intercalating into the membrane and stabilizing it. ${ }^{53}$ The membrane protecting activity of taurine is suggested to be related to its action on permeability to ions and water. ${ }^{47}$ In this

Figure 3. Effects of MiADMSA and taurine co-administration on arsenic concentration in blood and soft tissues. Figure shows significantly elevated level of arsenic in arsenic exposed animals which depleted more favorably during combined administration of taurine $(100 \mathrm{mg} / \mathrm{kg})$ and MiADMSA. MiA, monoisoamyl dimercaptosuccinic acid; As, arsenic. Values are mean \pm $\mathrm{SE} ; \mathrm{n}=5{ }^{*}, t, \ddagger, \S$ Means with matching symbol notations in each column are not significant at $5 \%$ level of significance. 
study, a direct correlation between arsenic concentration and tissue oxidative injury was noted. Depletion in tissue oxidative stress was accompanied by a decrease in tissue arsenic level. Similar observations were noted where taurine administration protected lead induced oxidative stress in rats. ${ }^{28}$ Taurine supplementation also provided significant recovery in depleted SOD activity. SOD, a metalloprotein accomplishes its antioxidant function by protecting the cells against the toxic effects of $\mathrm{O}^{2-}$ by catalyzing its dismutation reactions. A significant effect of taurine on liver and kidney GSSG was observed, while only a marginal protection was noticed on liver and kidney GSH after taurine administration. Although, it has been reported recently that taurine has a protective effect against thioacetamide hepatotoxicity in rats. ${ }^{54}$ and also decreases oxidative stress. ${ }^{55}$ Another new and interesting observation in the present study was that taurine at the dose of $100 \mathrm{mg} / \mathrm{kg}$ when administered along with MiADMSA provided more pronounced depletion of arsenic concentration in blood, liver and kidneys. This suggests that the antioxidative capacity of taurine becomes most effective only when it is administered along with the thiol chelators or taurine might be facilitating the entry of chelator to the intracellular sites thereby reducing arsenic concentration.

The results thus lead to conclude the beneficial role of taurine when administered along with a thiol chelator but still it remains to be seen if: (i) taurine is a better antioxidant than other available antioxidants in providing significant clinical recovery; (ii) a dose dependent study using a higher dose of taurine need to be attempted; (iii) the exact mechanism of action of taurine needs to be elucidated.

\section{Acknowledgements}

The authors thank Dr. R. Vijayaraghavan, the Director of the establishment, for his support and guidance. Swapnila Chouhan thanks Defence Research and Development Organization (DRDO) for the award of a Junior Research Fellowship.

\section{References}

1. World Health Organization (WHO). Guidelines for Drinking Water Quality, second ed. vol. WHO, Geneva, pp. 41-42.

2. Rahman MM, Chowdhury UK, Mukherjee SC, Mondal BK, Paul K, Lodh D, Biswas BK, Chanda CR, Basu, GK, Saha KC, Roy S, Das R, Palit SK, Quamruzzamam Q, Chakraborty D. Chronic arsenic toxicity in Bangladesh and West Bengal, India-A review and commentary. J Toxicol Clin Toxicol 2001; 39:683-700.

3. Parvez F, Chen Y, Argos M, Iftikhar Hussain AZM, Momotaj H, Dhar R, Van Green A, Graziano JH, Ahsan H. Prevalence of arsenic exposure from drinking water and awarenes of its health risks in a Bangladeshi population: results from a large population-based study. Environ Health Perspect 2006; 114:355-9.

4. Guha Mazumder DN. Effects of chronic intake of arsenic-contaminated water in liver. Toxicol Appl Pharmacol 2005; 206:169-75.

5. Flora SJS, Dube SN, Arora U, Kannan GM, Malhotra PR. Therapeutic potential of meso 2,3-dimercaptosuccinic acid or 2,3-dimercapto propane 1-sulphonate in chronic arsenic intoxication in rats. Biometals 1995; 8:111-6.

6. Flora SJS. Arsenic induced oxidative stress and its reversibility following combined administration of $\mathrm{N}$-acetylcysteine and meso 2,3-dimercaptosuccinic acid in rats. Clin Exp Pharmacol Physiol 1999; 26:865-869.

7. Flora SJS, Bhadauria S, Dhaked RK, Pant SC. Arsenic induced blood and brain oxidative stress and its response to some thiol chelators in male rats. Life Sci 2005; 77:2324-37.

8. Lee TC, Ho IC. Modulation of cellular antioxidant defense activities by sodium arsenite in human fibroblasts. Arch Toxicol 1995; 69:498-6.

9. Ercal N, Gurer-Orhan H, Aykin-Burns N. Toxic metals and oxidative stress part I: mechanisms involved in metal-induced oxidative damage. Curr Topic in Med Chem 2001; 1:52939

10. Hughes MF. Arsenic toxicity and potential mechanism of action. Toxicol Lett 2002; 133:116.

11. Maiti S, Chatterjee AK. Differential response of cellular antioxidant mechanism of liver and kidney to arsenic exposure and its relation to dietary protein deficiency. Environ Toxicol Pharmacol 2000; 8:227-35.
12. Flora SJS, Kumar P. Biochemical and Immunological evaluation of metal chelating drugs in rats. Drug Invest 1993; 5:269-73.

13. Flora SJS, Saxena G, Mehta A. Reversal of lead-induced neuronal apoptosis by chelation treatment in rats: role of ROS and intracellular $\mathrm{Ca}^{2+}$. J Pharmacol Exp Ther 2007; 322:10816.

14. Grandjean P, Jacobsen IA, Jorgensen PJ, Lings S, Andersen O. Treatment of chronic occupational lead poisoning with dimercaptosuccinic acid (DMSA). Ugeskr Laeger 1991; 7:2897-9.

15. Ercal N, Treeratphan P, Hammond TC, Matthews RH, Grannemann N, Spitz D. In vivo indices of oxidative stress in lead exposed $\mathrm{c} 57 \mathrm{bl} / 6$ mice are reduced by treatment with meso 2,3-dimercaptosuccinic acid or n-acetylcysteine. Free Radic Biol Med 1996; 21:157-61.

16. Jones MM, Singh PK, Gale GR, Smith AB, Atkins LM. Cadmium mobilization in vivo by intraperitoneal or oral administration of monoalkyl esters of meso 2,3-dimercaptosuccinic acid. Pharmacol Toxicol 1992; 70:336-43.

17. Rivera M, Levine DJ, Aposhian HV, Fernando Q. Synthesis and properties of monomethyl ester of meso dimercaptosuccinic acid and its chelators of lead (II), cadmium (II) and mercury (II). Chem Res Toxicol 1991; 4:107-14.

18. Xu C, Holscher MA, Jones MM, Singh PK. Effect of monoisoamyl meso 2,3-dimercaptosuccinate on the pathology of acute cadmium intoxication. J Toxicol Environ Hlth 1995; 45:261-77.

19. Flora SJS, Sekhar K. Chronic Arsenic Poisoning: Diagnosis and Treatment. In Pharmacological Perspectives of some Toxic Chemicals and Antidotes (S.J.S. Flora and James A Romano, Eds.), Narosa Publication, New Delhi, 2004; pp. 271-302.

20. Walker EM, Stone A, Milligan LB, Gale GR, Atkins LM, Smith AB, Jones MM, Singh PK, Basinger BA. Mobilization of lead in mice by administration of monoalkyl esters of meso2,3-dimiercaptosuccinic acid. Toxicol 1992; 76:79-87.

21. Kostial K, Blanusa M, Plasek LJ, Samarzila M, Jones MM, Singh PK. Monoisoamyl- and mono-n-hexyl-meso-2,3-dimercaptosuccinate in mobilizing $\mathrm{Hg} 203$ retention in relation to age of rats and route of administration. J Appl Toxicol 1995; 15:201-6.

22. Mehta A, Flora SJS. Possible Role of metal redistribution, hepatotoxicity and oxidative stress in chelating agents induced hepatic and renal metallothionein in rats. Food Chem Toxico 2001; 39:1029-38

23. Khandelwal S, Kachru DN, Tandon SK. Influence of metal chelators on metalloenzymes. Toxicol Lett 1987; 37:213-9.

24. Mehta A, Pant SC, Flora SJS. Monoisoamyl dimercaptosuccinic acid induced changes in pregnant female rats during late gestation and lactation. Reprod Toxicol 2006; 21:94-103.

25. Kim SJ, Ramesh C, Gupta H, Lee W. Taurine-diabetes interaction: from involvement to protection. J Biol Regul Homeost Agents 2007; 21:63-77.

26. Wright CE, Tallan HH, Lin YY. Taurine: biological update. Ann Rev Biochem 1986 55:427-53.

27. Huxtable RJ. Physiological action of taurine. Physiol Rev 1992; 72:101-63.

28. Flora SJS, Pande M, Bhadauria S, Kannan GM. Combined administration of taurine and meso-2,3-dimercaptosuccinic acid in the treatment of chronic lead intoxication in rats. Human Exp Toxicol 2004; 23:157-66.

29. Mishra D, Flora SJS. Quercetin administration during chelation therapy protects arsenic induced oxidative stress in mouse. Biol Trace Elem Res 2008; 122:137-47.

30. Berlin A, Schaller KH. European standardized method for the determination of delta aminolevulinic acid dehydratase activity in blood. Zeit Klin Chem Klin Biochem 1974 12:389-90.

31. Grandjean P. Occupational lead exposure in Denmark: screening with the haematofluorom eter. Brit J Indus Med 1979; 36:52-8.

32. Ellman GL. Tissue sulfhydryl groups. Arch Biochem 1959; 82:70-7.

33. Hissin PJ, Hilf R. A fluorometric method for the determination of oxidized and reduced glutathione in tissues. Anal Biochem 1976; 74:214-6.

34. Durak I, Canbolat O, Kavutch M. Activities of total, cytoplasmic and mitochondrial superoxide dismutase enzymes in sera and plural fluids from patients with lung cancer. J Clin Lab Anal 1996; 10:17-20.

35. Aebi H. Catalase. In Packer, L., ed. Methods in Enzymol. Orlando, FL, Academic Press, 1984, pp.125-6

36. Wilber KM, Baerheim F, Shapiro OW. The thiobarbituric acid reagent as a test for the oxidation of unsaturated fatty acid by various reagents. Arch Biochem Biphys 1949; 24:30411

37. Shila SE, Subathra M., Anusuya M, Chinnakkannu DP. Arsenic intoxication-induced reduction of glutathione level and of the activity of related enzymes in rat brain regions: reversal by DL-a-lipoic acid. Arch Toxicol 2005; 79:140-6.

38. Mishra D, Mehta A, Flora SJS. Reversal of hepatic apoptosis with combined administration of DMSA and its analogues in guinea pigs: Role of glutathione and linked enzymes. Chem Res Toxicol 2008; 21:400-7.

39. Mishra D, Flora SJS. Quercetin administration during chelation therapy protects arsenic induced oxidative stress in mouse. Biol Trace Elem Res 2008; 122:137-47.

40. Mishra D, Flora SJS. Differential oxidative stress and DNA damage in rat brain regions and blood following chronic arsenic exposure. Toxicol Indust Health 2008; In press.

41. Bhadauria S, Flora SJS. Response of arsenic induced oxidative stress, DNA damage and metal imbalance to combined administration of DMSA and monoisoamyl DMSA during chronic arsenic poisoning in rats. Cell Biol Toxicol 2007; 23:91-104. 
42. Klaassen CD. Heavy metals and heavy metal antagonist. In Gilman, A.G., Rall T.W., Nies A.S., Taylor P. (Eds.) The pharmacological basis of Therapeutics, McGraw-Hill, New York, 1996 pp. $1592-1614$.

43. Monteiro HP, Abdalla DSP, Augusto O, Bechara EJH. Free radical generation during $\delta$-aminolevulinic acid auto oxidation induction by hemoglobin and connections with porphyrinpathies. Arch Biochem Biophys 1989; 271:206-16.

44. Hermes-Lima M, Valle VG, Vercesi AE, Bechara EJ. Damage to rat liver mitochondria promoted by delta-aminolevulinic acid-generated reactive oxygen species: connections with acute intermittent porphyria and lead-poisoning. Biochim Biophys Acta 1991; 1056:5763.

45. Hermes-Lima M. How do $\mathrm{Ca}^{2+}$ and 5-aminolevulinic acid-derived oxyradicals promote injury to isolated mitochondria? Free Radic Biol Med 1995; 19:381-90.

46. Neal R, Cooper K, Kellogg G, Gurer H, Ercal N. Effects of some sulfur containing antioxidants on lead exposed lenses. Free Rad Bio Med 1999; 26: 239-43.

47. Timbrell JA, Seabra V, Waterfield CJ. The in vivo and in vitro protective properties of taurine. Gen Pharmacol 1995; 26:453-62.

48. Nittyen L, Nurminen ML, Korpela R, Vapaatalo H. Role of arginine, taurine and homocysteine in cardiovascular diseases. Ann Med 1999; 31:318-26.

49. Sole MJ, Jeejeebhoy KN. Conditioned nutritional requirements and the pathogenesis and treatment of myocardial failure. Curr Opin Clin Nutr Metab Care 2000; 3:417-24.

50. Qi B, Yamagami T, Naruse Y, Sokejima S, Kagamimori S. Effects of taurine on depletion of erythrocyte membrane Na- K ATPase activity due to ozone exposure or cholesterol enrichment. J Nutr Sci Vitaminol 1995; 41:627-34.

51. Redmond HP, Wang JH, Bouchier-Hayes D. Taurine attenuates nitric oxide and reactive oxygen intermediate dependent hepatocyte injury. Arch Surg 1996; 131:1287-388.

52. Cozzi R, Ricordy R, Bartolini F, Ramadori L, Perticone P, DeSalvia R. Taurine and ellagic acid: two differently acting natural antioxidants. Environ Mol Mutagen 1995; 26:248-54.

53. Gordon RE, Heller RF, Heller RF. Taurine protection of lungs in hamster model of oxidant injury: a morphologic time study of paraquat and bleomycin treatment. In Lombardini JB, Schaffer SW, Azuma J eds. Taurine: nutritional value and mechanisms of action. Plenum Press, New York, NY, 1992 pp. 319-23.

54. Balkan J, Dogru-Abbasoglu S, Kanbagli O, Cevikbas U, Aykac-Toker G, Uysal M. Taurine has a protective effect against thioacetamide-induced liver cirrhosis by decreasing oxidative stress. Hum Exp Toxicol 2001; 20:251-54.

55. Hagar HH. The protective effect of taurine against cyclosporine A-induced oxidative stress and hepatotoxicity in rats. Toxicol Lett 2004; 151:335-43. 


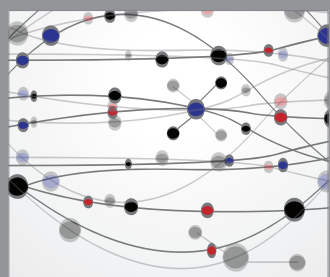

The Scientific World Journal
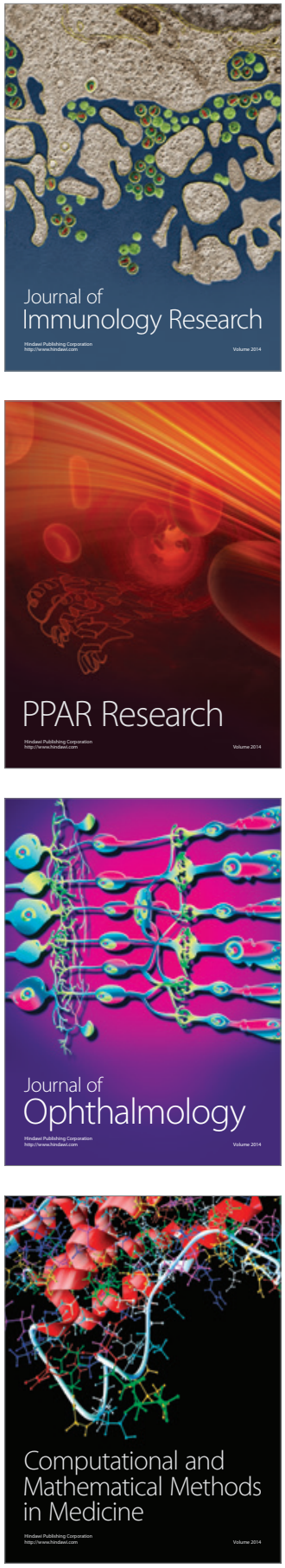

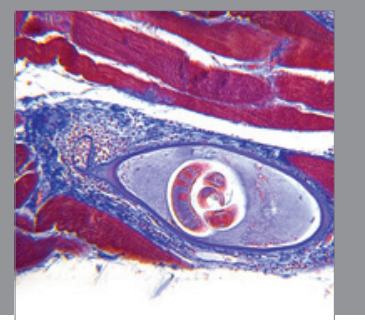

Gastroenterology

Research and Practice
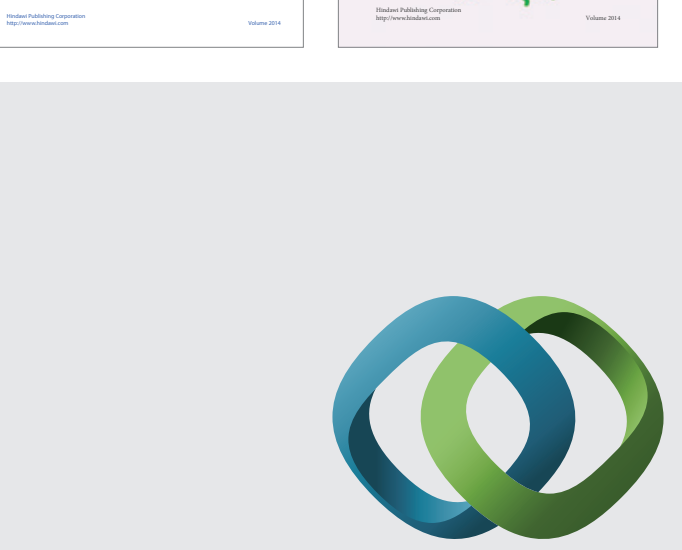

\section{Hindawi}

Submit your manuscripts at

http://www.hindawi.com
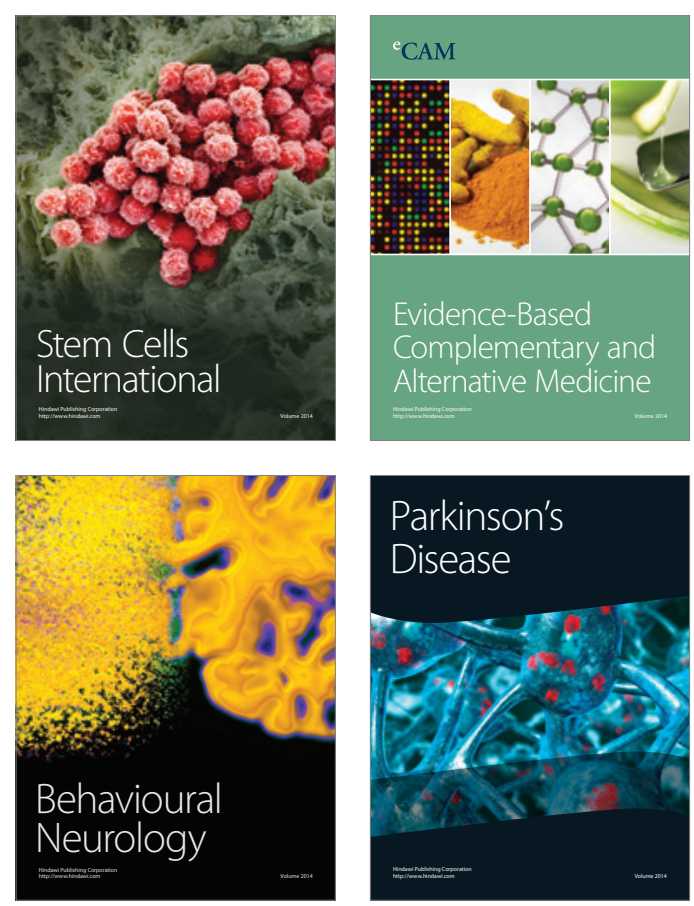

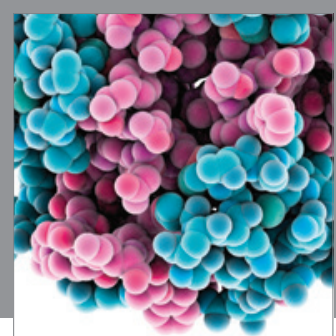

Journal of
Diabetes Research

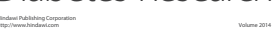

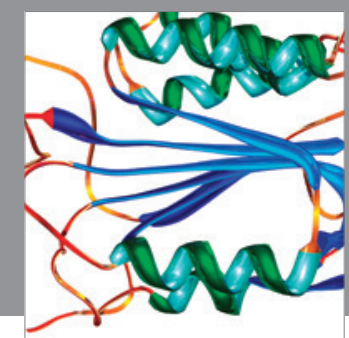

Disease Markers
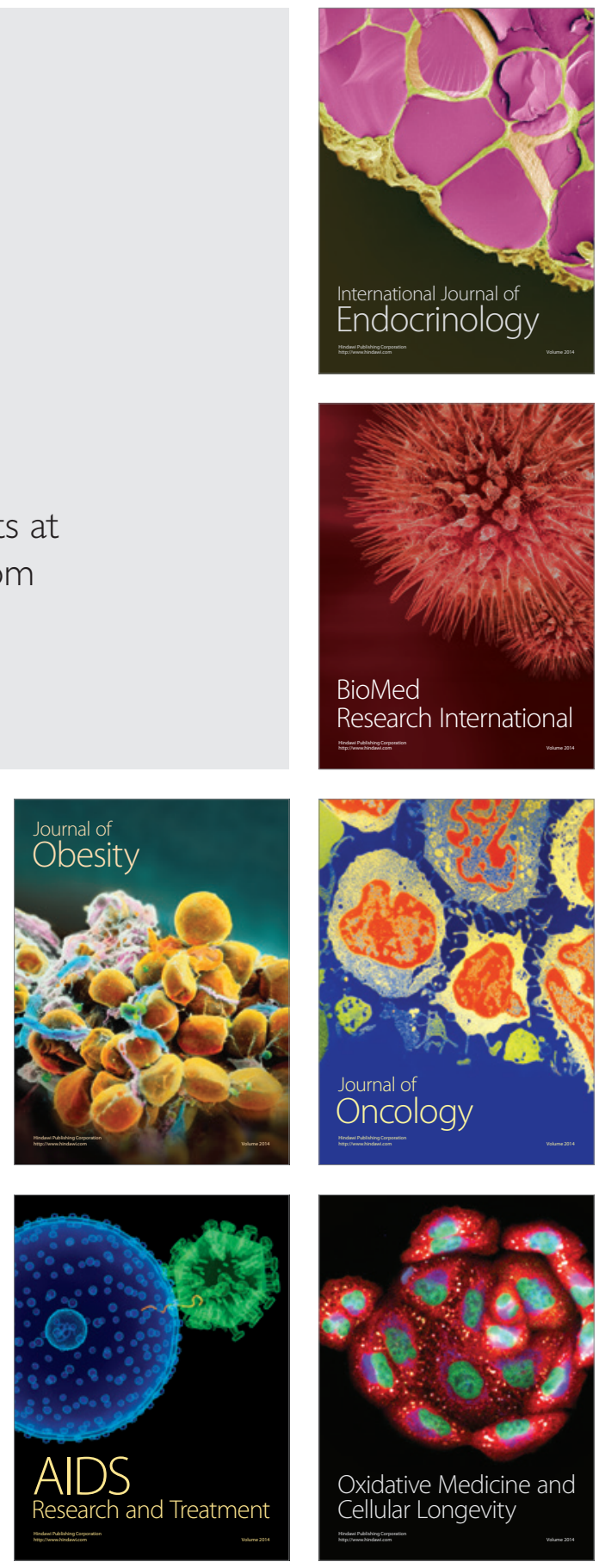